\title{
GÊNEROS ORAIS E NORMAS LINGUÍSTICAS: ANÁLISE DE UMA PROPOSTA DE ENSINO NO CONTEXTO DIGITAL
}

\section{ORAL GENRES AND LINGUISTIC NORMS: ANALYSIS OF A TEACHING PROPOSAL IN THE DIGITAL CONTEXT}

\author{
Luciana Chaves Pinheiro \\ Universidade Estadual do Ceará, Brasil \\ luciana-chaves@uol.com.br
}

\begin{abstract}
RESUMO: Em função da necessidade constante de análise e discussão das práticas que envolvem o processo de ensino e aprendizagem da oralidade e dos gêneros orais em materiais didáticos de Língua Portuguesa, neste artigo procura-se analisar um material didático digital (MDD) em suporte DVD, parte integrante da coleção (versão professor) "Português Linguagens", de William Roberto Cereja e Thereza Cochar Magalhães, que apresenta uma proposta de ensino com 14 gêneros orais. O foco será um dos aspectos dos gêneros tratado pelos autores: a adequação da linguagem à situação de produção. Nesse caso, evidencia-se a adequação ou não do uso dos termos norma-padrão e norma culta, tendo em vista o espaço discursivo, em que interlocutores, situação e contexto se encontram. Além disso, a partir dos gêneros selecionados na ferramenta digital, discute-se diferenças terminológicas e/ou conceituais de gênero discursivo e tipo de texto, como também a distinção entre gênero oral e oralização de texto escrito. $O$ aporte teórico é consti tuído, especialmente, por Bakhtin (1997), Bonini (2011), Marcuschi (2008, 2010, 2011), Travaglia (2017), Faraco e Zilles (2017), Bagno (2002) e pelos Parâmetros Curriculares Nacionais (BRASIL, 1998). Os resultados revelam que o material digital analisado, apesar de apresentar a possibilidade de explorar diversos gêneros autenticamente orais, apresenta equívocos quanto à utilização de conceitos e terminologia, como norma-padrão e norma culta, e limitações, considerando os posicionamentos teóricos apresentados neste trabalho, quanto à abordagem do ensino dos gêneros orais.
\end{abstract}

PALAVRAS-CHAVE: gêneros orais; norma linguística; material didático digital.

ABSTRACT: Due to the constant need for analysis and discussion of practices involving teaching and learning process of orality and oral genres in didactic material of Portuguese Language, in this article we analyse a digital didactic material in DVD support, an integral part of the collection (teacher's version) "Português Linguagens", written by William Roberto Cereja and Thereza Cochar Magalhães, which presents a teaching proposal with 14 oral genres. The focus is one of the aspects of the genres treated by the authors: the adequacy of the language to the context of production. In this case, the adequacy or not of the use of the terms standard-norm and culture-standard is evident, in view of the discursive space, where interlocutors, situation and context take place. In addition, from the selected genres in the digital tool, terminological and/or conceptual differences of discursive genre and type of text are discussed, as well as the distinction between oral genres and oralization of written text. The theoretical contribution is made by Bakhtin (1997), Bonini (2011), Marcuschi (2008, 2010, 2011), Travaglia (2017), Faraco and Zilles 
(2017), Bagno (2002) and the Parâmetros Curriculares Nacionais (BRASIL, 1998). The results show that the digital material analysed, despite presenting the possibility of exploring several authentically oral genres, presents misunderstandings regarding the use of concepts and terminology, as standard norm and cultured norm, and limitations, considering the theoretical positions presented in this paper, concerning the approach of teaching oral genres.

KEYWORDS: oral genres; language norm; digital didactic material.

\section{Introdução}

Nas últimas décadas, podemos perceber um progressivo crescimento de sugestões de trabalho com a oralidade e os gêneros orais nos livros didáticos de Português (doravante LDP). No entanto, diversos pesquisadores do estudo da linguagem têm destacado, ao longo desse período, problemas e limitações quanto à abordagem desse assunto nos materiais didáticos de Língua Portuguesa.

Faraco (2009), por exemplo, destacou a confusão quanto à utilização de conceitos e nomenclaturas, como norma-padrão e norma culta. Examinando os sentidos em que se usa o termo norma culta no Brasil, Faraco (2009) observou que a sua utilização indiscriminada terminou por recobrir conceitos que, na verdade, se aplicam a noções diferentes. Ele alerta para o fato de que muitas vezes a expressão norma culta é empregada como sinônimo de norma-padrão.

Já quanto à abordagem dos gêneros orais no ensino, Marcuschi (2008) constatou que, muitas vezes, não se leva em consideração um continuum entre oralidade e escrita, no qual se considera, por exemplo, o uso de uma linguagem mais informal tanto em uma conversa (forma oral) como em um bilhete (forma escrita) ou o uso de uma linguagem mais formal em uma conferência que, embora oral, aproxima-se da linguagem de um texto escrito formal.

Procurando, também, examinar o tratamento dado, pelos autores de materiais didáticos, à oralidade e aos gêneros orais na última década, Oliveira (2011) e Azevedo (2016) analisaram alguns livros didáticos de Língua Portuguesa ${ }^{1}$. Os exercícios, segundo Oliveira (2011), que se dedicavam à oralidade privilegiaram, de modo geral, a atividades de oralização da escrita ou atividades que culminavam com textos escritos. No que tange à relação fala-escrita e ao trabalho com a variação linguística, o material analisado, muitas vezes, evidenciou, segundo Azevedo (2016, p. 116), "um estudo voltado para a dicotomia entre as modalidades de uso da língua, sem desenvolver um trabalho mais profundo com as variações linguísticas e suas interfaces e contextualizações". Não verificou "um tratamento quanto aos graus de formalidade, tampouco aos fatores contextuais envolvidos" (AZEVEDO, 2016, p. 116). Apesar dos problemas relacionados à abordagem do estudo da língua oral nos materiais didáticos, os dois autores perceberam uma considerável presença dos gêneros orais nos LDP, como a entrevista, a exposição oral, o debate e outros.

Essa considerável presença do trabalho com gêneros orais é percebida, por exemplo, no material didático digital (MDD), em suporte DVD, parte integrante da coleção (ver são professor) "Português Linguagens", destinado ao ensino fundamental II, de William

1 Oliveira (2011) analisou cinco coleções do ensino fundamental II e Azevedo (2016) analisou um livro do ensino médio. Todas as coleções estão especificadas nas respectivas pesquisas. 
Roberto Cereja e Thereza Cochar Magalhães, que apresenta uma proposta de ensino com 14 gêneros orais em vídeo: conto maravilhoso oral, relato pessoal, opiniões orais ${ }^{2}$, poema declamado, discussão em grupo, debate deliberativo, notícia de rádio, entrevista oral, anúncio publicitário, reclamação oral, seminário, reportagem oral e debate público ${ }^{3}$. Segundo os autores, a ferramenta apresenta um trabalho "pioneiro e inovador" 4 . Tais qualificações talvez se devam ao fato de o MDD versar sobre um assunto que é pouco explorado na maioria dos livros didáticos de Português, os gêneros orais, e se apresentar em um formato digital. De fato, podemos supor que o vídeo poderá favorecer um trabalho produtivo e reflexivo dos gêneros orais, uma vez que é possível, por exemplo, permitir a observação e a reflexão do gênero em uso, a partir de contextos, interlocutores e práticas reais. Essa suposição nos impulsionou à avaliação dessa ferramenta digital, tendo em vista a superação ou não das principais limitações apontadas pelos pesquisadores anteriormente citados. Nosso foco será a análise de um dos aspectos tratados pelos autores no DVD: a adequação da linguagem à situação de produção ${ }^{5}$.

A fim de basilar nossa análise, iremos, na primeira parte do artigo, revisitar conceitos e estudos sobre normas linguísticas e gêneros orais, com base, especialmente, em Bakhtin (1997), Faraco e Zilles (2017), Marcuschi (2008, 2010), Travaglia (2017) e nos Parâmetros Curriculares Nacionais (PCN). Destacamos que Cereja e Magalhães (2014, p. 3) sugerem, no manual do professor, uma bibliografia que, segundo eles, "serviu de referência e apoio teórico para as várias ideias que nortearam o projeto da obra". Além dos PCN, foram citadas obras dos teóricos Mikhail Bakthin, Luiz Antônio Marcuschi, Joaquim Dolz, Bernard Schneuwly e Carlos Travaglia. Dessa forma, ressaltamos que nossa análise tem como base parte das teorias que embasaram os próprios autores da obra analisada. $\mathrm{Na}$ segunda parte, descreveremos, brevemente, o material didático digital. Em seguida, apresentaremos a análise do aspecto selecionado no MDD.

\section{Normas linguísticas e ensino}

Quando tratamos de ensino-aprendizagem de língua, faz-se necessário ter claras as concepções adotadas tanto do ponto de vista terminológico quanto do ponto de vista ideológico. Inicialmente, é preciso ter clareza quanto às diferenças conceituais e práticas no que se entende, por exemplo, por norma-padrão e norma culta.

A norma-padrão, segundo Faraco e Zilles (2017, p. 19),

2 Os autores consideram "opiniões orais" como gênero textual. Discutiremos essa classificação na análise.

3 A sugestão do MDD como parte integrante do estudo dos gêneros orais é marcada por meio de um ícone, no livro didático de todas as séries (6 ao $9^{\circ}$ ano) na primeira parte da seção denominada "Produção de textos". Essa primeira parte "desenvolve o conteúdo do ponto de vista teórico: partindo-se da observação de um texto representativo de determinado gênero (...)" (CEREJA; COCHAR, 2014a, p. 27). A segunda parte, denominada Agora é a sua vez, está voltada à produção do gênero, que deverá ser produzido, segundo os autores, "de acordo com uma ou mais propostas que permitam a aplicação dos aspectos teóricos desenvolvidos" (CEREJA; COCHAR, 2014a, p. 27).

4 Essa informação consta no MDD na seção "Sobre o DVD de gêneros orais".

5 Outros aspectos trabalhados pelos autores do MDD, interlocutores, tema, finalidade, estrutura, veículo e aspectos extraverbais, foram analisados por (PINHEIRO, 2014). 
é a expressão que designa a "norma normativa", isto é, o conjunto de preceitos estipulados no esforço homogeneizador do uso em determinados contextos. Nesse sentido, a norma-padrão é um modelo idealizador construído para fins específicos; não é, portanto, uma das tantas normas presentes no fluxo espontâneo do funcionamento social da língua, mas um construto que busca controlá-lo (FARACO; ZILLES, 2007, p. 19).

Já a norma culta "designa-se tecnicamente o conjunto das características linguísticas do grupo de falantes que se consideram cultos (ou seja, a 'norma normal' desse grupo específico)" (FARACO; ZILLES, 2017, p. 19). Essa comunidade de fala caracteriza-se por ter um certo grau de escolarização (curso superior completo) e/ou por saber fazer uso da linguagem de prestígio social (que se aproxima das normas estabelecidas nas gramáticas normativas) nas situações em que se exige um grau alto de formalidade da língua. Assim, não são somente as normas que constam nas gramáticas normativas que servirão de referência para a linguagem desses falantes, mas também a própria manifestação linguística desses sujeitos materializada no dia a dia ou nas mídias sociais. O que podemos observar, nesse caso, é que a noção de competência linguística defendida por esse viés passa do ideal para o real.

Essa manifestação linguística, no entanto, não é única, linear, uma vez que um mesmo falante pode alternar entre diferentes formas linguísticas nas mais diversas situações discursivas, por onde transita o assunto tratado, o gênero discursivo utilizado, a identidade social do interlocutor, o grau de conhecimento entre os interlocutores, entre outros aspectos. Essas diversas situações determinarão, por exemplo, o grau de formalidade da língua, que pode ser alto, mediano e baixo. Um professor universitário que domina a norma culta deverá, por exemplo, fazer uso de uma linguagem mais informal (grau baixo de formalidade) num restaurante com amigos, enquanto na sala de aula, ou em uma palestra, deverá fazer uso de uma linguagem mais formal e mais próxima da escrita (grau médio ou alto de formalidade).

Além da situação ou do contexto (fatores externos ao falante), a língua também pode ser influenciada por fatores ligados ao próprio falante (idade, sexo, classe social, escolaridade). No caso da escolaridade, é fundamental destacar que quanto mais baixo for o nível escolar do sujeito, maior é a possibilidade de sua fala se distanciar da norma culta, já que ele terá tido uma oportunidade menor de conhecer a norma-padrão na escola e, em consequência, maior será a possibilidade de o sujeito ser estigmatizado socialmente. Isso, segundo Almeida e Zavam (2004, p. 256), acontece porque

\footnotetext{
a tendência ao julgamento linguístico reflete um julgamento da estrutura social (socioeconômica) da comunidade. Sendo assim, quando se julga o falar de um grupo, primeiramente se está julgando o grupo pela sua posição dentro da sociedade (prestigiada ou desprestigiada), depois, como consequência, tem-se avaliação linguística (falar prestigiado ou estigmatizado) (ALMEIDA; ZAVAM, 2004, p. 256).
}

Em outras palavras, podemos dizer que as pessoas pertencentes às classes sociais mais desfavorecidas e provenientes de certas regiões do Brasil, como o Nordeste, por exemplo, sofrem, quase sempre, preconceitos pela posição social a que pertencem e pelo espaço geográfico de origem ${ }^{6}$, e, como consequência, pela variedade linguística que do-

6 A variação ligada ao espaço geográfico conduz, segundo Pretti (1994, apud Almeida; Zavam, 2004, p. 
minam (variedade não-padrão). Nesse último caso, surge o que Bagno (2002) denominou de preconceito linguístico. Esse ponto de vista evidencia que a questão da norma está vinculada não somente a um conceito terminológico ou estilístico de ordem gramáticoestrutural, mas também a uma ideologia. Assim, defendemos que, embora seja competência da escola assegurar aos alunos o acesso à norma culta, é preciso não a eleger exclusivamente como norteadora do ensino de línguas, uma vez que o universo da linguagem e da cultura se constrói na dialogização das vozes sociais (BAKHTIN, 1997). Por isso, torna-se fundamental entrar em contato com as diferenças, porque em Brasil (1998, p. 31) "o igual é aquele com quem se tem afinidade e identidade, mas é o diferente que gera conflito, choque, confronto de visões, questionamentos e nos mostra aspectos da realidade que não estamos vendo".

Nesse ponto, os PCN nos convidam a pensar na possibilidade de conviver, quanto à linguagem, não só com quem temos afinidade e identidade, mas também com quem nos mostra aspectos diferentes que conhecemos. Nesse contexto, trazer, para sala de aula, mídias e/ou ferramentas digitais que contemplem a língua nas suas mais variadas manifestações nos parece produtivo como forma de minimizar a ocorrência do preconceito linguístico e de não reforçar, por meio da linguagem, a exclusão social.

Outro aspecto importante a ser destacado quanto ao ensino da língua é considerar que o discurso não ocorre de forma isolada, mas diz respeito "aos usos coletivos da lín gua que são sempre institucionalizados, isto é, legitimados por alguma instância da atividade humana" (MARCUSCHI, 2011, p. 20). Esses usos coletivos institucionalizados, com as quais as pessoas se comunicam, sejam através da fala ou da escrita, foram denominados por Bakhtin (1997) de gêneros do discurso ${ }^{7}$. Passaremos, então, a abordar, tangencialmente, esse tema, para, em seguida, discutirmos os gêneros orais, relacionando-os ao ensino.

\section{Gêneros orais e ensino}

No Brasil, as discussões sobre os gêneros do discurso se propagaram, especialmente a partir do ano 1980, baseadas nas ideias de Bakhtin (1997), que os definiu como "tipos relativamente estáveis de enunciados" (BAKHTIN, 1997, p. 279), com determinadas regularidades quanto conteúdo temático (o que é ou pode tornar-se dizível por meio do gênero), a construção composicional (estrutura) e estilo (engloba as formas de realização linguísticas, como escolhas lexicais e recursos fraseológicos).

Com a publicação dos $\mathrm{PCN}$, os gêneros do discurso ${ }^{8}$ passaram a ser inseridos mais fortemente no espaço da sala de aula como objeto de ensino, principalmente, pelo

245), a uma oposição fundamental: linguagem urbana e linguagem rural.

7 Apesar da diluição das fronteiras entre as denominações "gêneros discursivos" e "gêneros textuais", assumiremos o primeiro termo neste trabalho.

8 Embora o nome de Bakhtin ou de outros membros do Círculo de Bakhtin não sejam mencionados no texto dos PCN, é possível identificar uma forte filiação teórica pelos termos utilizados e pelos posicionamentos assumidos em relação à linguagem, como, por exemplo, "gêneros são (...) formas relativamente estáveis de enunciados" (BRASIL, 1998, p. 21). É importante destacar que esse documento adotou a concepção de "gênero discursivo" sob a denominação "gênero textual", posição assumida também por alguns estudiosos da Linguística Textual, dentre eles Marcuschi (2008). 
viés dos livros didáticos, que assumiram as orientações do documento e incorporaram essa nova prática de tratamento com a linguagem ${ }^{9}$. Desde então, os gêneros discursivos têm sido alvo crescente de estudos e investigação, não só porque surgem novos gêneros, pelas mais diversas necessidades de comunicação, como também porque nem sempre 0 conceito de gêneros é algo consensual.

Quanto às questões terminológicas e/ou conceituais dos gêneros orais, por exemplo, algumas dúvidas podem surgir: um artigo científico lido em voz alta em uma conferência deve ser caracterizado como um gênero oral? E o que dizer da peça teatral, que embora necessite, de um modo geral, da oralidade para sua realização, apoia-se, quase sempre, em um texto previamente escrito? Trata-se de um gênero oral ou escrito?

Nesse sentido, Travaglia (2017) defende que a simples oralização de um texto escrito não o torna um gênero oral. Assim, torna-se fundamental considerar o gênero como oral com base em duas características: ter como suporte a voz humana e ser produzido por dada comunidade para ter uma realização oral, independentemente de ter ou não uma versão escrita. Dessa forma, um artigo científico, mesmo que seja lido em voz alta, não será um gênero oral, já que não foi produzido para ser realizado oralmente, mas para existir na forma escrita. Por outro lado, podem ser considerados gêneros orais aqueles que têm uma versão escrita, mas que se realizam oralmente, usando a voz como suporte. É o caso das peças teatrais, telenovelas, recontos etc.

Outras questões quanto ao uso de terminologias exigem esclarecimentos e discussões, como a diferença entre gênero e tipo textual, e entre gênero e hipergênero.

Marcuschi (2008, p. 154) afirma que

os gêneros textuais são os textos que encontramos em nossa vida diária e que apresentam padrões sociocomunicativos característicos definidos por composições funcionais, objetivos enunciativos e estilos concretamente realizados na integração de forças históricas, sociais, institucionais e técnicas (MARCUSCHI, 2008, p. 154).

Já tipo textual, segundo Marcuschi (2008, p. 154), "designa uma espécie de construção teórica \{em geral uma sequência subjacente aos textos\}". Esse autor destacou a importância de se considerar as "sequências tipológicas" ou "sequências textuais", entendidas como estruturas subjacentes ao gênero. Dessa forma, um gênero é composto por sequências textuais, que podem ser configuradas como sequência narrativa, sequência descritiva, sequência expositiva e sequência injuntiva.

Embora Marcuschi (2008) considere a exposição oral em seminário um gênero discursivo, Bonini (2011) o classifica como hipergênero. Segundo este autor, um gênero

9 Além dos PCN, a importância de considerar concepções discursivas no estudo da linguagem e os gêneros do discurso como objeto de ensino também foi incorporada pelas matrizes de referência de Língua Portuguesa para a avaliação do ENEM (Sistema de Avaliação do Ensino Médio) e do SAEB (Sistema de Avaliação da Educação Básica). Isso pode ser comprovado, no primeiro sistema, nas competências da área $5 \mathrm{e}$ da área 7, que destacam a importância de trabalhar com diferentes gêneros e de relacionar "textos com seus contextos, mediante a natureza, função, organização, estrutura das manifestações, de acordo com as condições de produção e recepção" (competência 5). No segundo sistema, o tópico II dos descritores do $9^{\circ}$ ano, por exemplo, refere-se às "implicações do suporte, do gênero e/ou do enunciador na compreensão do texto" e destaca também a preocupação de abordar diferentes gêneros no contexto da sala de aula. 
pode se agrupar para formar uma unidade maior, um macroenunciado, ou seja, um hipergênero. Nessa perspectiva, o seminário ou o telejornal são hipergêneros, pois são constituídos de vários gêneros, como, por exemplo, a reportagem, a notícia, a entrevista.

Nesse caso, a escolha da terminologia (gênero ou hipergênero) pode ampliar ou determinar a percepção do objeto de estudo. Por exemplo, classificar o seminário como um hipergênero é perceber também que vários gêneros (entrevista, notícia, piada) se entrecruzam em um único gênero e, por isso, suscita o reconhecimento de estruturas, estilos e graus de oralidade diferentes. Para isso, torna-se necessário olhar para o espaço discursivo e observar o gênero discursivo se realizando no seu contexto real, de uso.

Quanto ao ensino dos gêneros orais, os PCN, apoiados nos pressupostos bakhtinianos, defendem que a escola precisa se concentrar na língua oral materializada nos gêneros secundários, ou seja, aqueles que dizem respeito a textos mais complexos, mais formais, que pertencem a esferas institucionalizadas na sociedade. Dolz et al. (2010, p. 147) também defendem que "é papel da escola levar os alunos a ultrapassar as formas de produção oral cotidiana (gêneros primários) para os confrontar com outras formas mais institucionais", como a exposição oral, a entrevista, o debate, dentre outros. O que não se pode esquecer, no entanto, é que a escola deve "propor situações didáticas nas quais essas atividades façam sentido de fato, pois é descabido treinar um nível mais formal da fala, tomando como mais apropriado para todas as situações" (BRASIL, 1998, p. 25).

No momento em que a escola assume o compromisso de ampliar a competência comunicativa do aluno, tornando-os ouvintes e produtores de gêneros orais mais institucionalizados, é preciso, como ponto de partida, deixar para trás a concepção que considera a fala como desorganizada, não planejada e heterogênea e a escrita como organizada, estável e homogênea. O que precisa ser considerado é a existência de um contínuo ou gradação entre fala e escrita. Autores como Marcuschi (2010) e Rojo e Schneuwly (2006) defendem essa posição ao afirmar que o oral pode se aproximar mais da escrita, como no caso da exposição oral, ou pode estar mais distanciado, como na conversação cotidiana.

A partir desses posicionamentos teóricos e conceituais, faremos uma análise dos gêneros orais que compõem o material didático digital. Antes da análise, descrevemos, no próximo tópico, nosso objeto de estudo.

\section{A descrição do MDD (DVD)}

O material didático digital em DVD tem como conteúdo propostas de ensino de 14 gêneros orais em vídeo, distribuídos da seguinte forma: conto maravilhoso oral, relato pessoal e opiniões orais ( $6^{\circ}$ ano); poema declamado, discussão em grupo, debate deliberativo, notícia de rádio e entrevista oral ( $7^{\circ}$ ano); texto teatral, anúncio publicitário, reclamação oral ${ }^{10}$ e seminário ( $\left.8^{\circ} \mathrm{ano}\right)$; reportagem oral e debate regrado público $\left(9^{\circ} \mathrm{ano}\right)$.

Alguns desses gêneros que compõem o MDD, segundo Cereja e Cochar (2014a, p. 14), foram extraídos da mídia a partir de situações reais de interação em que o evento co municativo aconteceu, como a reportagem televisiva, o texto teatral, o anúncio publicitário, a notícia de rádio. A maioria dos gêneros, ainda segundo os autores, foi produzida para o 
MDD e procuram reproduzir situações em que pessoas simulam uma situação real de ocorrência desses gêneros. Destacamos que a sugestão do uso da ferramenta digital é marcada por meio de um ícone, no livro didático de todas séries ( $6^{\circ}$ ao $9^{\circ}$ ano), na primei ra parte da seção denominada "Produção de textos".

Todos os gêneros que compõem o MDD apresentam, de maneira geral, a mesma sequência metodológica, que pode ser dividida, basicamente, em três blocos ${ }^{11}$.

No primeiro bloco (abertura), é apresentado o nome do gênero que será analisado. Em seguida, um locutor solicita oralmente que os ouvintes "prestem atenção aos seguintes elementos": "Quem são os interlocutores?; Qual é o tema abordado?; Qual é a finalidade do texto?; Como o texto está organizado?; Há adequação da linguagem à situação de produção?; Como o texto é veiculado?"12 Vejamos uma tela que apresenta parte desses elementos:

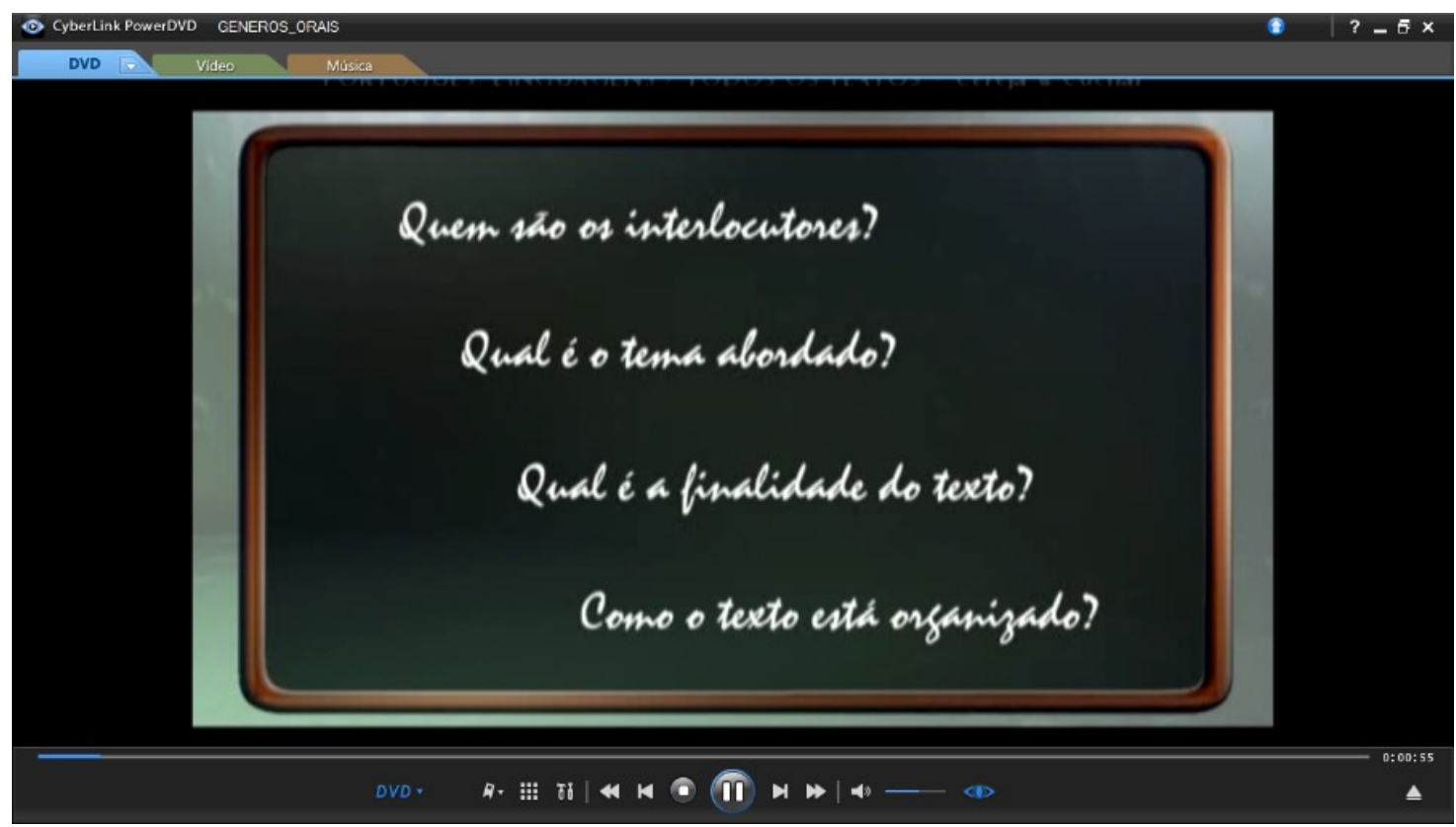

Figura 1: Recorte de uma das telas de abertura dos gêneros do MDD.

Fonte: DVD de gêneros orais (parte integrante da coleção Português: Linguagens, 2014, versão livro do professor).

No segundo bloco (apresentação), um modelo ou uma simulação de um gênero é apresentado. Ao que se supõe, espera-se que o aluno, ao assistir à apresentação, relacione aquilo que está sendo visto com os elementos destacados no primeiro bloco.

Durante a apresentação dos vídeos, uma legenda, que aparece em alguns momentos na parte inferior da tela, vai destacando alguns elementos, principalmente quanto à estrutura (elementos composicionais) e quanto aos "aspectos extraverbais" relacionados aos gêneros, como "demonstração de alegria, entonação, velocidade da fala, movimentos corporais, relacionamento respeitoso entre o grupo, direção do olhar"13 e outros. Vejamos

11 Os autores do MDD parecem querer focar em uma das características dos gêneros discursivos, a "relativa estabilidade", considerada, dentro outros aspectos, a partir do ponto de vista temático (tema), composicional (estrutura) e estilístico (linguagem)

12 Um locutor lê essas perguntas que estão escritas na tela.

13 Denominação e exemplificação extraídos do MDD. 
um exemplo:

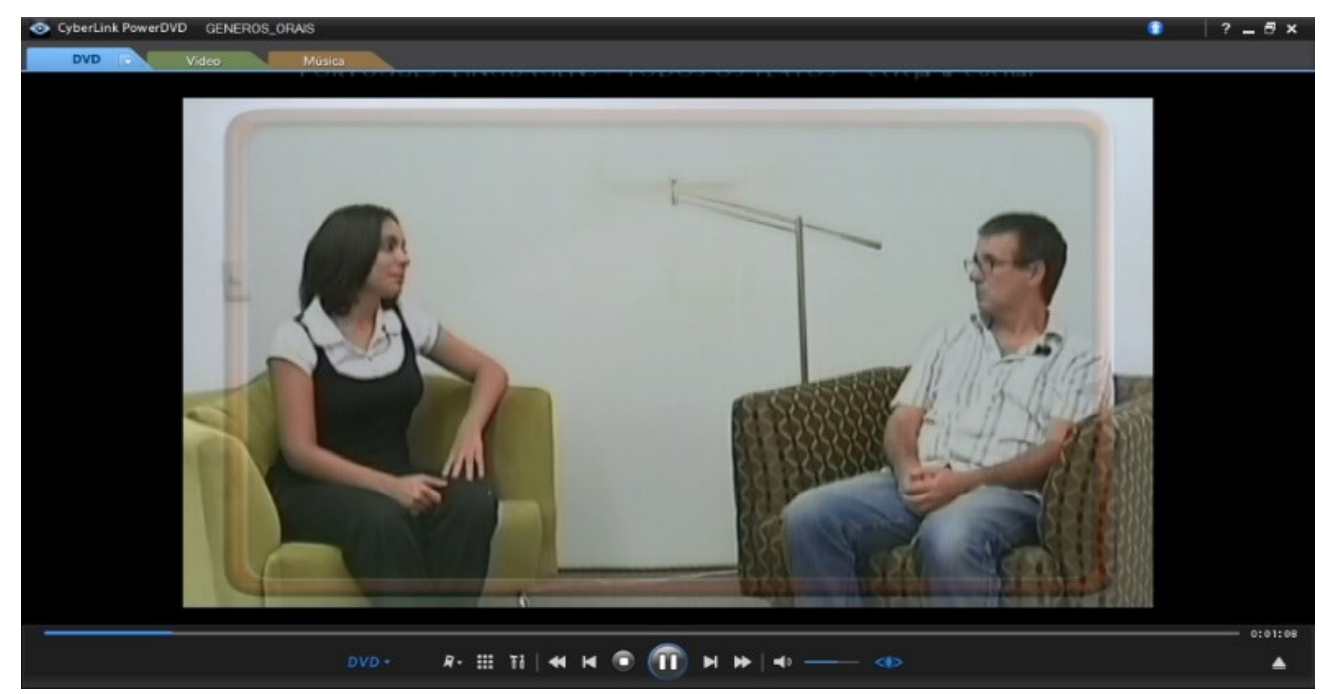

Figura 2: Recorte do vídeo que exibe o gênero entrevista oral no MDD.

Fonte: DVD de gêneros orais (parte integrante da coleção Português: Linguagens, 2014, versão livro do professor).

No último bloco (fechamento), são apresentadas "sugestões de respostas", com foco nos elementos centrais seguintes: interlocutores, tema, finalidade, linguagem, estrutura, veículo e aspectos extraverbais. Nesse bloco, os autores procuram responder às perguntas propostas na abertura e destacar alguns aspectos extraverbais observados durante a apresentação do vídeo. A seguir, um exemplo:

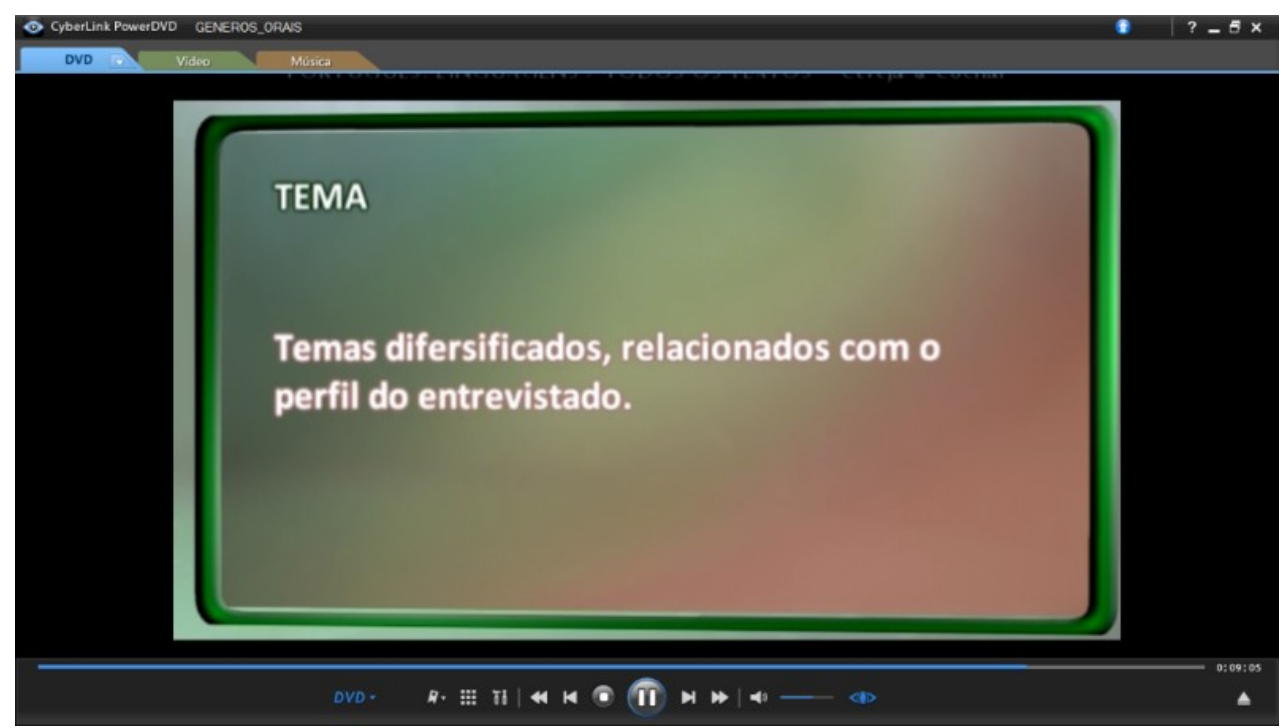

Figura 3: Recorte do vídeo que exibe o gênero entrevista oral do MDD.

Fonte: DVD de gêneros orais (parte integrante da coleção Português: Linguagens, 2014, versão livro do professor).

No próximo tópico, discutiremos um dos aspectos trabalhados pelos autores do material didático digital (MDD): a adequação da linguagem à situação de produção dos gêneros orais. 


\section{Análise do MDD}

Para facilitar nossa análise, agrupamos, no quadro a seguir, as respostas que respondem à pergunta "Há adequação da linguagem à situação de produção?"14

Quadro 1: Há adequação da linguagem à situação de produção?

\begin{tabular}{|c|c|}
\hline Gênero discursivo & Linguagem \\
\hline Relato pessoal & $\begin{array}{l}\text { Norma-padrão da língua, podendo ser menos ou mais formal, de- } \\
\text { pendendo da situação de produção }\end{array}$ \\
\hline Discussão em grupo & Coloquial \\
\hline Entrevista oral & $\begin{array}{l}\text { Norma-padrão da língua, podendo ser menos ou mais formal, de- } \\
\text { pendendo da situação de produção }\end{array}$ \\
\hline Seminário & Norma-padrão da língua \\
\hline Debate deliberativo & $\begin{array}{l}\text { Norma-padrão da língua, podendo ser menos ou mais formal, de- } \\
\text { pendendo da situação de produção }\end{array}$ \\
\hline Debate regrado público & $\begin{array}{l}\text { Norma-padrão da língua, podendo ser menos ou mais formal, de- } \\
\text { pendendo da situação de produção }\end{array}$ \\
\hline Anúncio publicitário & $\begin{array}{l}\text { Adequada ao perfil do anúncio e do público a que se destina, po- } \\
\text { dendo ser menos ou mais formal }\end{array}$ \\
\hline Conto Maravilhoso oral (reconto) & $\begin{array}{l}\text { De acordo com a norma-padrão da língua, podendo ser menos ou } \\
\text { mais formal, dependendo do perfil das personagens e das situações }\end{array}$ \\
\hline Notícia de rádio (áudio) & Norma padrão da língua \\
\hline Opiniões orais & $\begin{array}{l}\text { Linguagem coloquial, podendo ser menos ou mais formal, depen- } \\
\text { dendo da situação de produção }\end{array}$ \\
\hline Reclamação oral (rádio) & Não há referência à linguagem \\
\hline Reportagem oral (TV) & $\begin{array}{l}\text { De acordo com a norma-padrão da língua, podendo ser menos ou } \\
\text { mais formal, dependendo da situação de produção }\end{array}$ \\
\hline Texto teatral & $\begin{array}{l}\text { Varia de acordo com o perfil de cada personagem e das situações } \\
\text { encenadas }\end{array}$ \\
\hline Poema declamado & Varia de acordo com o conteúdo do poema \\
\hline
\end{tabular}

Fonte: Autoria própria.

Inicialmente, se voltarmos nosso olhar para a pergunta que se propõe servir de orientação para o aluno enquanto assiste ao vídeo "há adequação da linguagem à situação de produção?", o que podemos perceber é que não há uma relação coerente entre a pergunta e as respostas sugeridas nesse tópico, uma vez que a pergunta remete a uma resposta positiva ou negativa, que poderia suscitar uma discussão em torno de uma justificativa para a resposta. Na verdade, seria essa justificativa que poderia conduzir o aluno a observar todos os falantes que participam de cada gênero, a fim de verificar se eles conseguem adequar a sua linguagem com base na situação, no contexto e no gênero.

14 Focaremos, em nossa análise, o uso das terminologias norma-padrão e norma culta. Dessa forma, excluímos do quadro um aspecto explorado pelos autores do MDD nesse tópico: "uso de recursos linguísticos e coesivos, como e, aí, eu concordo, eu discordo etc.". 
Quanto à escolha dos gêneros orais, precisamos considerar dois aspectos, tendo em vista o aporte teórico deste trabalho.

Não consideramos "opiniões orais" ou "textos de opinião" um gênero do discurso. Nesse caso, consideramo-lo "tipo de texto" ou "sequência de texto" (MARCUSCHI, 2008), uma vez que se trata de uma estrutura que compõe os gêneros do discurso. Além disso, também não consideramos poema declamado um gênero oral, já que o poema não foi produzido para ser realizado oralmente, mas para ser oralizado a partir de sua forma escrita.

Quanto às respostas ao tópico "linguagem", a generalização e a desconsideração da situação, do contexto e dos interlocutores causam contradições e falhas quanto à escolha de aspectos/termos que se relacionam aos fenômenos linguísticos que ocorreriam em cada gênero.

Para analisarmos as sugestões de respostas, consideramos importante, em primeiro lugar, destacar como os próprios autores definem e abordam o termo "norma-padrão" na coleção. No livro destinado ao $6^{\circ}$ ano (2014b, p. 42), a expressão é definida como "uma referência, uma espécie de modelo ou de 'lei' que normatiza o uso da língua, falada ou escrita". Além disso, os autores afirmam que

A norma-padrão não existe como uma língua de fato, pois ninguém fala português em norma-padrão em todos os momentos da vida. Ela é um modelo, uma referência que orienta os usuários da língua sempre que precisam usar o português de modo mais formal. (CEREJA; COCHAR, 2014b, p. 42).

Ainda segundo os autores, existiriam variedades do português que se aproximam mais da norma-padrão e, por isso, seriam mais prestigiadas socialmente. Seria o caso das variedades urbanas de prestígio "também conhecidas como norma culta", que "são empregadas pelos falantes urbanos, mais escolarizados e de renda mais alta" (CEREJA; COCHAR, 2014b, p. 43).

Dessa forma, podemos considerar que identificar a linguagem dos falantes nesses gêneros, mesmo imaginando o que normalmente ocorre em situações reais de produção, como "norma-padrão" não nos parece coerente se levarmos em consideração que, segundo os próprios autores, a norma-padrão não representa uma variedade real da língua, mas uma variedade ideal, que, segundo os autores, parece ser sinônimo de alto grau de formalidade. Se a norma culta ou a variedade urbana de prestígio é, conforme defendem os autores, aquela empregada pelos falantes urbanos mais escolarizados, que fariam uso da norma-padrão em situações mais formais, parece-nos mais adequado considerar, em uma análise mais geral, esses termos como mais apropriados para classificar a linguagem dos falantes que normalmente participam das situações de interação reais em que esses gêneros se realizam.

É importante também considerar que norma culta falada se difere da norma culta escrita. Se observarmos, por exemplo, a fala da entrevistadora Daniela Dias Ferreira, no gênero entrevista, no MDD, poderemos extrair um exemplo dessa distinção.

A entrevistadora, ao dar início à entrevista com o cartunista Laerte, faz o seguinte comentário: "Bom, pra começar nosso bate-papo, eu acho que vou começar a fazer uma pergunta que todo mundo que gosta do seu trabalho quer saber, né?".

No contexto, tanto o uso da contração "pra" como a ausência da preposição "de" antes do pronome relativo "que" são manifestações linguísticas comuns na fala de falan- 
tes cultos, embora a norma-padrão considere apenas a preposição "para" em situações formais e determine o uso da preposição "de" no segundo caso. Entretanto, vale ressaltar que, em uma situação de escrita formal, essas exigências precisariam ser atendidas por esses falantes, como, por exemplo, em uma entrevista divulgada na modalidade escrita.

Isso comprova que a norma-padrão não foi, em alguns casos, a referência para os participantes das situações de interação em que os gêneros analisados realizaram. Esse fato, inclusive, ocorre com muitos falantes cultos com nível superior que, muitas vezes, buscam nas normas cultas, que se modificam por meio do uso que esses próprios falantes fazem dela, uma referência para sua fala.

Outro fato a ser observado é considerar que a linguagem dos participantes desses gêneros pode "ser menos ou mais formal, dependendo da situação de produção". Nesse ponto, é importante relembrar as ideias de Bakhtin quanto à intenção de classificar os gêneros mais formais (gêneros secundários) e mais informais (gêneros primários). O autor destacou a importância de considerar esses dois eixos como interdependentes. Isso quer dizer que é preciso considerar que o grau de formalidade na língua poderá variar dentro de um mesmo gênero, tendo em vista, por exemplo, o assunto, o relacionamento pessoal dos interlocutores ou o grau de escolaridade dos participantes do gênero.

No relato pessoal, apresentado no MDD, por exemplo, há cinco participantes (pai, mãe e três filhas) que possuem graus de escolaridade diferentes, como também, está claro que possuem um tempo diferente de vivência e de experiência com a língua oral for mal. Embora todos participem de uma situação em que é exigido um monitoramento maior da fala, esses fatores que o diferenciam contribuem para um grau também diferente de monitoramento e formalidade da língua. Dessa forma, o pai (Amyr Klink) e a mãe (Marina Klink) conseguem fazer mais uso da norma culta, elevando, assim, o grau de formalidade da língua. Isso pode ser observado, por exemplo, na fala da mãe quando, mais de uma vez, faz a opção pelo pronome "nós" em vez da expressão "a gente", como em "Antes de nós voltarmos para o Brasil, esse ano, o desafio foi elas fazerem um novo tesouro". Já as três crianças fazem uso exclusivamente da expressão "a gente" e utilizam mais termos próprios de uma linguagem menos monitorada e mais informal, como é o caso do termo "um monte de" ou do termo "ruim", que foi usada, por uma das garotas, como uma palavra paroxítona.

Já no gênero discussão em grupo, o tipo de linguagem destacada foi a "coloquial". Se observarmos o comportamento dos alunos que participam da simulação do gênero, podemos perceber que é bastante semelhante ao que acontece no gênero debate regrado público. Nos dois casos, os jovens fazem uso de linguagem informal; no debate, inclusive, há a presença do uso de gírias.

Dessa forma, não parece adequado dizer que no debate regrado os participantes falam de acordo com a norma-padrão, uma vez que a norma padrão, a rigor, não existiria porque é apenas ideal, enquanto no gênero discussão em grupo, os falantes falam de acordo com uma linguagem "coloquial", termo que não constitui necessariamente uma oposição ao termo norma- padrão, mas se refere ao grau de formalidade de um registro de fala.

$\mathrm{Na}$ verdade, dever-se-ia dizer que os dois gêneros exigem norma culta (o aluno deve adquirir essa variante na escola), mas em graus de formalidade distintos. No debate regrado, o grau seria mais alto e na discussão em grupo seria mediano ou baixo. 
A adequação da linguagem à situação foi considerada apenas em dois gêneros: anúncio publicitário e peça teatral. Nesses casos, o perfil do anúncio e do público a que se destina (anúncio) e o perfil de cada personagem e das situações encenadas (peça teatral) foram destacados como reguladoras da manifestação linguística. Essa adequação, no entanto, deveria ter sido considerada, de fato, em todos os gêneros discursivos trabaIhados no MDD.

Assim, podemos concluir que problemas apontados por pesquisadores há décadas, a partir da análise de materiais didáticos de LP, como a utilização equivocada de termos como norma-padrão e norma culta e a desconsideração dos graus de formalidade da língua e dos fatores contextuais envolvidos na realização dos gêneros discursivos, não foram superados no MDD analisado nessa pesquisa.

\section{Considerações finais}

Neste artigo, tivemos como objetivo principal analisar uma ferramenta digital educacional destinada ao ensino de Língua Portuguesa no ensino fundamental II.

Quanto aos resultados da análise, alicerçada nos teóricos apresentados, foi possível constatar, dentro dos limites estabelecidos para esse trabalho, alguns pontos positivos, quanto à proposta de ensino da oralidade e dos gêneros orais, como: a diversidade de gêneros explorados na ferramenta, levando em conta os diferentes domínios discursivos, e a possibilidade de promover discussões, interações, a partir de gêneros autenticamente orais (e não apenas textos oralizados).

Entretanto, apesar de tais pontos positivos, pontuamos, tendo em vista o aporte teórico apresentado, algumas inadequações, como: a) a desconsideração dos interlocutores, da situação e do contexto de uso dos gêneros orais; b) a desconsideração quanto ao tratamento dos graus de formalidade nos gêneros, e c) falhas quanto à escolha de aspectos e termos relacionados aos fenômenos linguísticos.

Sugerimos que todas as inadequações apontadas nessa investigação sejam revistas para que o objeto digital analisado avance quanto à resolução dos problemas apontados, há décadas, por pesquisadores.

Acreditamos que, para isso, não se pode perder de vista a necessidade de um diálogo constante entre cientistas/teóricos, especialistas educacionais, autores de livros didáticos, professores e alunos, uma vez que o saber científico se transforma junto com a sociedade, ao longo do tempo, exigindo um repensar frequente das práticas de ensino.

\section{Referências}

ALMEIDA, N.; ZAVAM, A. (org.). A língua na sala de aula: questões práticas para um ensino produtivo. Fortaleza: Perfil Cidadão, 2004.

AZEVEDO, V. T. G. Oralidade no livro didático: análise e concepção docente. 2016. 139f. Dissertação (Pós-Graduação em Letras) - Universidade Federal de Sergipe, São Cristóvão, 
2016.

BAGNO, M. Preconceito linguístico: o que é, como se faz. 15. ed. Loyola: São Paulo, 2002.

BAKHTIN, M. Estética da criação verbal. 2. ed. São Paulo: Martins Fontes, 1997.

BONINI, A. Mídia/suporte e hipergênero: os gêneros textuais e suas relações. RBLA, Belo Horizonte, v. 11, n. 3, p. 679-704, 2011. Disponível em: http://www.scielo.br/pdf/rbla/v11n3/05.pdf. Acesso em: 09 abr. 2018.

BRASIL, Ministério da Educação. Parâmetros Curriculares Nacionais - Ensino Fundamental - Língua Portuguesa. Brasília: SEF/MEC, 1998.

CEREJA, W.; COCHAR, T. Manual do Professor. In: Português Linguagens. $6^{\circ}$ ano. 8. ed. (reformulada). São Paulo: Atual, 2014a.

CEREJA, W.; COCHAR, T. Português Linguagens. $6^{\circ}$ ano. 8. ed. (reformulada). São Paulo: Atual, 2014b.

DOLZ, J.; SCHNEUWLY, B. O oral como texto: como construir um objeto de ensino. In: SCHNEUWLY, B., DOLZ, J. (org.) Gêneros orais e escritos na escola. 2. ed. Campinas (SP): Mercado de Letras, 2010, p. 125 a 155.

FARACO, C. A. Norma culta brasileira: desatando alguns nós. São Paulo: Parábola Editorial, 2009.

FARACO, C. A, ZILLES, A. M.. Para conhecer norma linguística. São Paulo: Contexto, 2017.

MARCUSCHI, L. Produção textual, análise de gêneros e compreensão. São Paulo: Parábola Editorial, 2008.

MARCUSCHI, L. Da fala para a escrita: atividades de retextualização. 10. ed. São Paulo: Cortez, 2010.

MARCUSCHI, L. A. Gêneros Textuais: configurações, dinamicidade e circulação. In: KARWOSKI, A. M.; GAYDECZKA, B.; BRITO, K. S. (org.). Gêneros textuais: reflexões e ensino. São Paulo: Parábola, 2011, p. 17-31.

OLIVEIRA, M. L. G. A oralidade no livro didático de Língua Portuguesa. V Encontro de pesquisa, ensino e extensão da Faculdade Senac. 2011. Disponível em: http://www.faculdadesenacpe.edu.br/encontro-de-ensino-

pesquisa/2011/V/anais/poster/010_2011_poster.pdf. Acesso em: 02 fev. 2018.

PINHEIRO, L. C. Ferramentas digitais e livro didático: análise de uma proposta de ensino de oralidade. Dissertação (mestrado em Linguística Aplicada). Universidade Estadual do 
Ceará. Fortaleza: CE, 2014.

ROJO, R.; SCHNEUWLY, B. As relações oral/escrita nos gêneros orais formais e públicos: o caso da conferência acadêmica. Linguagem em Discurso, v. 6, n. 3, 2006. Disponível em:

http://www.portaldeperiodicos.unisul.br/index.php/Linguagem_Discurso/article/view/346. Acesso em: 15 fev. 2017.

TRAVAGLIA, L. C. Gêneros orais - conceituação e classificação. Olhares \& Trilhas, Uberlândia, vol. 19, n. 2, p. 1-8, jul./dez. $2017 . \quad$ Disponível em: http://www.ileel.ufu.br/anaisdosilel/wp-content/uploads/2014/04/silel2013_1528.pdf. Acesso em: 20 abr. 2018.

Recebido em dia 20 de julho de 2018. Aprovado em dia 24 de agosto de 2018. 